\title{
Assessment of the efficacy and safety of steam vein sclerosis as compared to classic surgery in lower extremity varicose vein management
}

\author{
Witold Woźniak ${ }^{1}$, Robert K. Mlosek ${ }^{2}$, Piotr Ciostek ${ }^{1}$ \\ ${ }^{1}$ First Department of General and Vascular Surgery, Second Faculty of Medicine with the English Division and the Physiotherapy \\ Division, Medical University of Warsaw, Warsaw, Poland \\ 2Department of Ultrasonographic Diagnostics and Mammography, Second Faculty of Medicine with the English Division \\ and the Physiotherapy Division, Medical University of Warsaw, Warsaw, Poland
}

Videosurgery Miniinv 2015; 10 (1): 15-24

DOI: $10.5114 /$ wiitm.2015.48573

\begin{abstract}
Introduction: For the last 10 years, endovenous thermal ablation methods have gradually predominated over the classic Babcock procedure in varicose vein treatment. Steam vein sclerosis is the newest thermal ablation technique. Aim: To assess the efficacy and safety of steam vein sclerosis as compared to the Babcock procedure in lower extremity varicose vein treatment.

Material and methods: One hundred and two adult subjects with varicose veins of clinical grade C2 to C6 according to the CEAP classification, treated with varicose vein surgery between 2010 and 2012, were enrolled in the study. These were subdivided into two groups: the study group of 52 patients treated with endovenous steam vein sclerosis and the control group of 50 patients treated with the Babcock procedure. A single lower extremity with isolated great or small saphenous vein insufficiency was operated on in each subject. The groups were compared for demography, disease severity, involved veins, potential perioperative and postoperative complications, as well as treatment efficacy based on the VCSS score reduction.

Results: There were no statistically significant differences between the groups in terms of demography, disease severity, involved veins, or perioperative and postoperative complications. The treatment efficacy of both methods, assessed based on the recurrence rate and the quantitative VCSS score reduction, was similar. Clinically significant recanalisation was observed in 1 (1.9\%) patient in the study group.

Conclusions: The efficacy and safety analysis shows that steam vein sclerosis is a safe, simple method which can be recommended as effective varicose vein treatment.
\end{abstract}

Key words: steam, endovenous, varicose veins, percutaneous ablation, chronic venous insufficiency.

\section{Introduction}

The Babcock procedure, which has remained standard varicose vein surgery for over 100 years, includes great saphenous vein ligation, stripping and phlebectomy [1, 2]. Yet, it is associated with relatively high rates of such complications as pain, haematoma, wound infection, lymphocele, lymphorrhoea or neuropathies due to skin nerve damage [3, 4]. It can also cause serious complications such as haemorrhage, femoral artery injury, deep vein thrombosis (DVT) or pulmonary embolism [5, 6]. Venous stripping is typically performed under general or conduction anaesthesia.

\section{Address for correspondence}

Witold Woźniak, First Department of General and Vascular Surgery, Second Faculty of Medicine with the English Division and the Physiotherapy Division, Medical University of Warsaw, 8 Kondratowicza St, 03-242 Warsaw, Poland, phone: +48 508 158 172, e-mail: drww@onet.pl 
It requires hospitalisation, and the usual recovery period, before the patient is fit to work, is approximately 4 weeks [7]. Despite the theoretically correct assumptions, this conventional surgery has turned out to be a non-radical one. It is linked to a high long-term recurrence rate, reaching even $60-80 \%[8,9]$.

The first venous thermal ablation techniques, including endovenous laser ablation (EVLA) or radiofrequency ablation (RFA), emerged and became popular in the late 1990s and early 2000s. One of the pioneers of thermal venous ablation was Mieczysław Politowski (1920-1984), a Polish surgeon, who achieved thermal obliteration through electrocoagulation in the early 1960s. Unfortunately, the method was abandoned soon after that, due to such complications as skin burns, wound infections and pulmonary embolism [10].

The first results of using water steam for thermal ablation were published in 2009 [11]. It was the third method to use high temperature in varicose vein treatment. The steam vein sclerosis (SVS) system, as is the proper name of the technique, consists of a steam generator, an adapter and a compressor. The steam is applied into the vein through a special catheter consisting of a $60 \mathrm{~cm}$ long metal pipe with a blunt tip and two side openings at the tip. On the outside, the pipe is wrapped in a plastic sheath with $1 \mathrm{~cm}$ graduations. The outer diameter of the catheter is $1.2 \mathrm{~mm}$ and its internal diameter (i.e. the working canal) is only $100 \mathrm{~nm}$. The compressed steam is force pushed into this narrow space. After it passes the catheter canal, the steam cools down to $120^{\circ} \mathrm{C}$, and this is the actual temperature of the steam applied into the vein. It was calculated that a single steam impulse releases approximately $60 \mathrm{~J}$ of energy per $1 \mathrm{~cm}$ long vein segment (linear endovenous energy

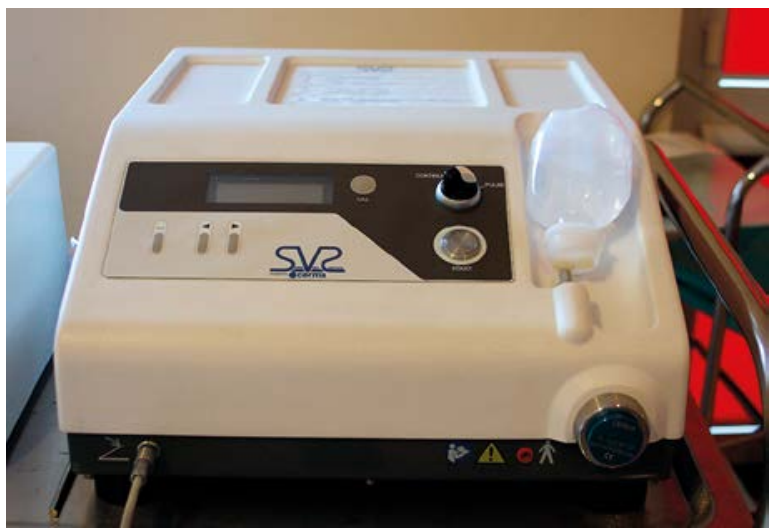

Photo 1. SVS generator density - LEED). As with EVLA and RFA, thermal energy released from the steam during SVS damages all three vein layers, which results in vessel obliteration and sclerosis. Newer histopathological analyses of the damage caused to the vascular wall and the adjacent tissue due to thermal ablation did not show significant differences between the EVLA, RFA and SVS methods, despite significant differences in the qualitative properties of the applied energy [12].

\section{Aim}

The aim of the present study was to assess the efficacy and safety of steam vein sclerosis as compared to the conventional surgery (Babcock procedure) in lower extremity varicose vein treatment.

\section{Material and methods}

\section{Patients}

The comparative study of steam vein sclerosis and the Babcock procedure in treatment of lower extremity varicose veins was conducted at the First Department of General and Vascular Surgery, Second Faculty of Medicine of the Medical University of Warsaw and Life-Med Clinic in Grodzisk Mazowiecki between 2010 and 2012. The patients with varicose veins clinical grade C2 to C6 according to the CEAP classification and isolated great or small saphenous vein insufficiency, regardless of their sex and age, were enrolled in the study. Only one limb of a given patient was included in the analyses. The exclusion criteria included: a history of deep vein thrombosis, congenital vasculopathies, thrombophilia, severe systemic disease (cancer, severe cardiovascular disease, severe renal failure, severe hepatic failure, advanced atherosclerosis involving lower extremities, etc.) as well as pregnancy and breastfeeding. The patients were randomised to either SVS or a control group.

\section{SVS group}

The group consisted of 52 patients who were treated with endovenous steam vein sclerosis. The procedure was performed under aseptic conditions using the CERMA SVS generator (CermaVein, Archamps, France) (Photos 1-3).

First, the insufficient venous trunk segments were identified precisely and the ultrasound-guided mapping of the varicose veins was performed. The vein diameter was measured $4 \mathrm{~cm}$ below the saphe- 


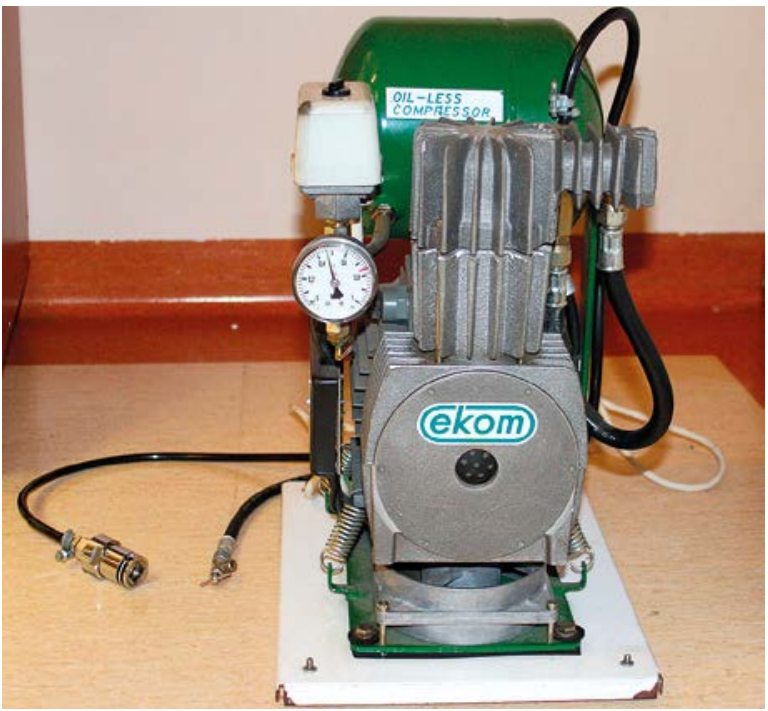

Photo 2. Dental compressor

nofemoral junction or saphenopopliteal junction. Then, after prior skin decontamination and using sterile drapes to cover the surgical field, the phlebotomy to the great saphenous vein (GSV) or small saphenous vein (SSV) was created at the lowest insufficient point. The procedure was performed under local anaesthesia (lignocaine hydrochloride 1\%). It was ultrasound-guided with the probe placed longitudinally or transversely, wrapped in a sterile sleeve (Metset, $14 \times 250 \mathrm{~cm}$ ). Similarly, the keypad of the ultrasound scanner was covered with sterile foil (Steri-Drape $91 \mathrm{~cm})$. The patient was placed in the reverse Trendelenburg position during the phlebotomy. The vein was punctured using the 16G 2" cannula. Subsequently, the SVS catheter was inserted. Two phlebotomies were performed for venous trunks longer than $60 \mathrm{~cm}$. The first phlebotomy was performed at the upper $1 / 3$ of the crus and was used for thermal ablation of the proximal vein segment, whereas the second phlebotomy, performed at the ankle or at the lower $1 / 3$ of the crus, was used for steam ablation of the distal vein segment. If the phlebotomy failed, venesection technique was used instead. The location of the SVS catheter tip was determined using ultrasound, and it was attempted to position it at 2-3 cm from the saphenofemoral junction or saphenopopliteal junction. Having fixed the catheter in place, the patient was placed in a Trendelenburg position with the deviation angle of $15-30^{\circ}$ and anaesthetised. All patients were operated on under tumescent anaesthesia applied to the area along the vein. The anaesthetic fluid, whose composition is

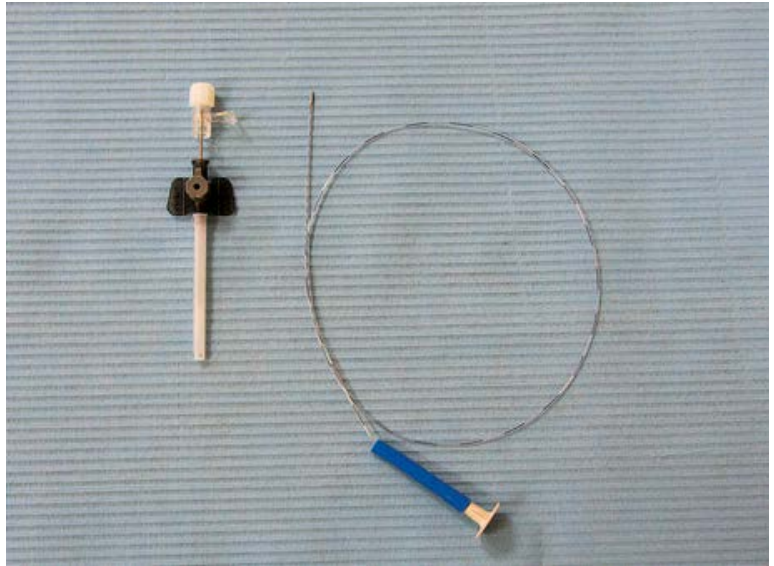

Photo 3. Assembled vein cannulation set (cannula and SVS catheter)

itemised in Table I, was administered subcutaneously (s.c.). The ultrasound-guided procedure aimed at surrounding the vein with the anaesthetic fluid by means of applying $10 \mathrm{ml}$ of fluid per $1-\mathrm{cm}$-long vein segment. A roller pump (Dispenser DP20, Nouvag, Switzerland) equipped with an assembled infusion set and the 22G 3.5" Spinal Needle were used for administering the tumescent fluid (Photo 4).

The adapter connecting the SVS catheter with the generator was protected with a sterile sleeve (Metset, $14 \times 250 \mathrm{~cm}$ ). The $50 \mathrm{ml}$ bags containing sterile distilled water, attached to the generator, were the steam source for the apparatus. The standard dental compressor attached to the generator provided adequate pressure for the system. Thermal ablation was performed at the power settings recommended by the manufacturer, applying 4-8 impulses onto the first vein segment followed by $2-4$ impulses onto each additional $1 \mathrm{~cm}$ long vein segment. The impulses were applied one-by-one. Their number per each $1 \mathrm{~cm}$ long vein segment was determined based on vein diameter measured at baseline. Hence,

Table I. Tumescent anaesthesia fluid - composition

\begin{tabular}{|lc|}
\hline Name of ingredient & Amount [ml] \\
\hline $0.9 \%$ Sodium chloride & 440 \\
\hline 1\% Lignocaine hydrochloride & 50 \\
\hline $0.5 \%$ Bupivacaine & 8 \\
\hline $0.1 \%$ Epinephrine & 0.5 \\
\hline 8.4\% Sodium bicarbonate & 6.5 \\
\hline
\end{tabular}




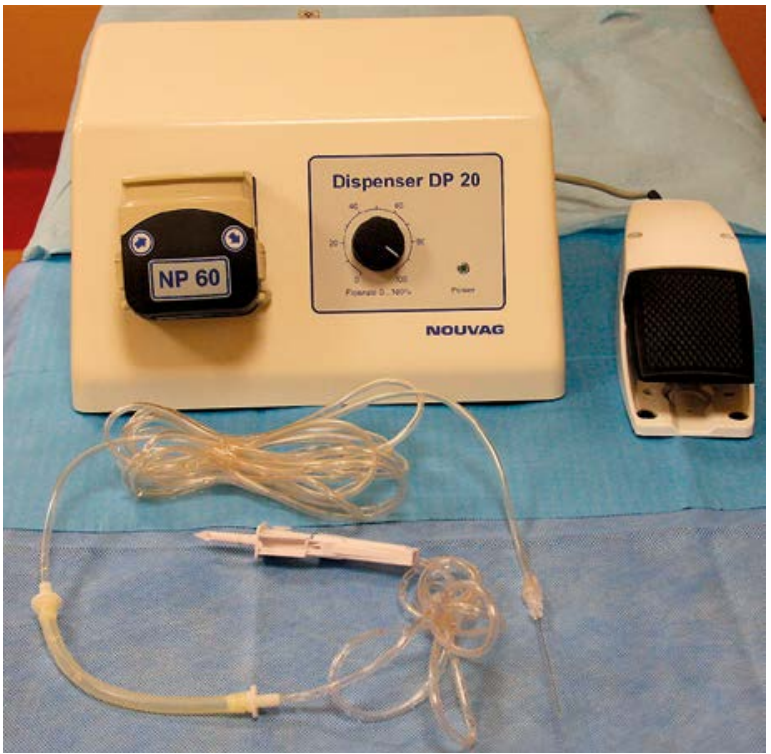

Photo 4. Roller pump and the infusion set for tumescent fluid administration

2 impulses per $1 \mathrm{~cm}$ long segment were applied onto blood vessels up to $7 \mathrm{~mm}$ in diameter. Likewise, $3 \mathrm{im}$ pulses were applied per segment onto veins whose diameter fell in the range of 7-12 $\mathrm{mm}$, and 4 impulses per segment onto blood vessels whose diameter exceeded $12 \mathrm{~mm}$. Steam generation stopped at $2 \mathrm{~cm}$ before catheter removal so as to avoid skin burns. In cases with known indications, miniphlebectomy and ligation of the insufficient perforator veins were performed after the actual ablation. At the end of the procedure, a sterile dressing was applied to the postoperative wound and all patients started wearing second degree compression stockings immediately afterwards. After a 2-hour observation period, the patients were discharged home.

\section{Control group}

The control group consisted of 50 patients treated with the Babcock procedure. Patient preparation was identical as in the SVS group. After precise ultrasound-guided mapping, the procedure was performed in the operational theatre. Conduction anaesthesia and light sedation were used. The patient was lying supine (GSV incompetence) or prone (SSV incompetence) with a slightly elevated leg, when the incision was performed in the inguinal area or popliteal fossa, respectively. A significant stage of the procedure was to identify and ligate all collateral veins and accessory saphenous veins in the inguinal area. A similar sequence was followed when operating on the SSV accessed through the popliteal fossa. Then, an incision was created at the end of the incompetent GSV or SSV segment (as identified previously during the ultrasound scan). Nabatoff probe was inserted proximally from the periphery, but the stripping itself was performed peripherally starting at the inguinal area or the popliteal fossa. Similarly to the comparator, this procedure was also followed by miniphlebectomy and ligation of the insufficient perforator veins in indicated cases. The sterile dressing was placed on the postoperative wound after the surgery, and the compression therapy with two layers of elastic (compression) bandage was started immediately. The patients were discharged home at $24 \mathrm{~h}$ following the surgery.

\section{Postoperative management}

Low molecular weight heparin (LMWH) administered for 7 days and the second degree postoperative compression therapy continued for 8 weeks were routinely used as part of thrombosis prevention in both groups (SVS and controls).

\section{Comparative study}

Both groups were compared in terms of age, sex, body mass index (BMI), stage of the disease using CEAP classification and Venous Clinical Severity Score (VCSS), parameters and types of involved veins, as well as potential perioperative and postoperative complications. The treatment efficacy was compared using the VCSS score reduction parameter, which was calculated at baseline and at 6 months postoperatively for each patient. The patients were monitored postoperatively using ultrasound scans performed at regular intervals on the day of surgery (day 0), at 1 week and 1 month following the surgery, and subsequently every 6 months.

\section{Statistical analysis}

The values of the ordinal variables were compared using the Kruskal-Wallis test. It is a rank test, which does not take into account the interval differences of a given variable. The post-hoc analysis included the Bonferroni-corrected Mann-Whitney U-test.

\section{Results}

\section{Group comparison at baseline}

A total of 102 patients aged $27-79$ years old treated for lower extremity varicose veins were enrolled 
Table II. Demographic data comparison - SVS group vs. control group

\begin{tabular}{|lcc|}
\hline Parameter & SVS group & $\begin{array}{c}\text { Control } \\
\text { group }\end{array}$ \\
\hline No. of patients & 52 & 50 \\
\hline Age range [years] & $28-79$ & $27-73$ \\
\hline Mean age [years] & 51.44 & 53.04 \\
\hline Women, $n$ (\%) & $43(82.7)$ & $39(78)$ \\
\hline Men, $n$ (\%) & $9(17.3)$ & $11(22)$ \\
\hline $\begin{array}{l}\text { Body mass index, range } \\
\text { (mean) [kg/m }{ }^{2} \text { ] }\end{array}$ & $19-42(28.09)$ & $22-45(28.9)$ \\
\hline GSV insufficiency, $n(\%)$ & $48(92.3)$ & $48(96)$ \\
\hline SSV insufficiency, $n$ (\%) & $4(7.7)$ & $2(4)$ \\
\hline
\end{tabular}

in the study. There were $82(80.4 \%)$ women and 20 (19.6\%) men in the group. Table II shows the comparison of demographic data between the two groups.

Disease severity (clinical grade) according to the CEAP classification and patient distribution (\%) between groups are presented in Figure 1.

The demographic aspects (number of patients, age, sex, BMI, treated vein, disease stage by CEAP classification) were comparable between the groups, with no statistically significant differences.

\section{Comparison of selected surgical parameters}

Table III shows clinical parameters of veins treated with individual intervention types. In 49 patients (94.2\%) from the SVS group, additional collateral vein phlebectomy was performed apart from the standard insufficient segment ablation. It was abandoned in other subjects due to advanced trophic lesions secondary to the varicose veins. Perforator vein ligation was additionally performed in 39 (75\%) patients.

Similarly, in 49 (96\%) controls additional collateral vein phlebectomy was performed apart from the standard stripping procedure. It was abandoned in only one subject in this group, due to advanced trophic lesion on the crus. Ligation of the insufficient perforator veins was performed in $36(72 \%)$ patients.

No technical difficulties were observed when passing the SVS catheter through the obliterated vein segments. Technical difficulties when passing the Nabatoff probe through the involved vessel, which required additional incisions and segmental phlebectomy, were encountered in $6(12 \%)$ patients

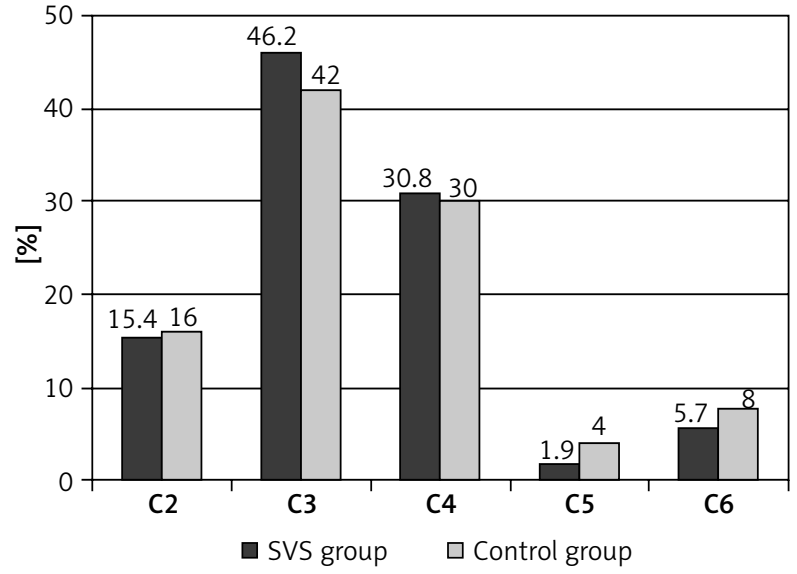

Figure 1. Distribution of patients in both groups according to disease severity assessed using clinical grade of CEAP classification, expressed as \%

from the control group. No intraoperative complications were noted in either of the two groups.

The type, segment length and clinical characteristics of the involved veins were similar in both groups, with no statistically significant differences. A relatively large difference, however, was found when analysing the technical difficulties encountered upon the attempt to pass the instrument through the venous lumen. The problem did not occur in the SVS group, and its incidence in the control group was $12 \%$. The difference, however, is not statistically significant.

\section{Comparison of postoperative complications}

Primary closure of the GSV and SSV was achieved in all patients from the SVS group. The ultrasound

Table III. Clinical characteristics of veins treated in both patient groups

\begin{tabular}{|lcc|}
\hline Venous parameters & SVS group & Control group \\
\hline GSV: & $24-80 \mathrm{~cm}$ & $12-72 \mathrm{~cm}$ \\
\hline Length range & $54.6 \mathrm{~cm}$ & $49.14 \mathrm{~cm}$ \\
\hline Mean length & $3-18 \mathrm{~mm}$ & $3-20 \mathrm{~mm}$ \\
\hline Diameter range & $6.43 \mathrm{~mm}$ & $7.14 \mathrm{~mm}$ \\
\hline Mean diameter & & \\
\hline SSV: & $12-26 \mathrm{~cm}$ & $22-38 \mathrm{~cm}$ \\
\hline Length range & $20 \mathrm{~cm}$ & $30 \mathrm{~cm}$ \\
\hline Mean length & $4-10 \mathrm{~mm}$ & $3-8 \mathrm{~mm}$ \\
\hline Diameter range & $6.62 \mathrm{~mm}$ & $5.5 \mathrm{~mm}$ \\
\hline Mean diameter & & \\
\hline
\end{tabular}


Table IV. Postoperative complications in the SVS and control groups

\begin{tabular}{|lcc|}
\hline Complication type & $\begin{array}{c}\text { SVS group } \\
n(\%)\end{array}$ & $\begin{array}{c}\text { Control group } \\
n(\%)\end{array}$ \\
\hline Deep vein thrombosis & $0(0)$ & $0(0)$ \\
\hline Pulmonary embolism & $0(0)$ & $0(0)$ \\
\hline $\begin{array}{l}\text { Inguinal lymphocele } \\
\text { Permanent skin } \\
\text { pigmentation }\end{array}$ & Not applicable & $1(2)$ \\
\hline $\begin{array}{l}\text { Transient skin } \\
\text { pigmentation }\end{array}$ & $4(7.6)$ & $2(4)$ \\
\hline $\begin{array}{l}\text { Skin burns } \\
\text { Permanent saphenous } \\
\text { nerve injury }\end{array}$ & $1(1.9)$ & $0(0)$ \\
\hline $\begin{array}{l}\text { Transient saphenous } \\
\text { nerve injury }\end{array}$ & $0(9.6)$ & $6(12)$ \\
\hline $\begin{array}{l}\text { Long-segment (over } 5 \mathrm{~cm}) \\
\text { recanalisation }\end{array}$ & $1(1.9)$ & Not applicable \\
\hline $\begin{array}{l}\text { Short-segment (below } \\
5 \text { cm) recanalisation }\end{array}$ & $4(7.7)$ & Not applicable \\
\hline $\begin{array}{l}\text { Recurrent varicose veins } \\
\text { (1) }\end{array}$ & $6(12)$ & \\
\hline
\end{tabular}

scan performed in the controls did not show any stripped vessel remainders either.

No complications of tumescent anaesthesia were observed in the SVS group, whereas 1 young female patient from the control group (2\%) developed post-lumbar puncture syndrome after conduction anaesthesia. The described symptoms resolved after fluid administration and anti-inflammatory treatment (diclofenac $50 \mathrm{mg}$ ).

Table IV presents the types and number of postoperative complications across both study groups.

One patient in the control group developed postoperative lymphocele in the inguinal region, which required three repeated punctures and compression therapy.

Linear skin pigmentation involving the lower $1 / 3$ of a thigh and/or upper $1 / 3$ of a lower leg occurred in $5(9.5 \%)$ patients from the SVS group. It resolved completely in 1 case and decreased significantly, becoming almost invisible over the 1-year follow-up. Similar pigmentation, which decreased in intensity over the follow-up period, occurred in 2 (4\%) patients from the control group.

Saphenous nerve injury manifesting as paraesthesia and sensory loss occurred in 7 (13.4\%) patients in the SVS group. In 2 cases the symptoms resolved completely after 6-9 months and remained persistent in other subjects. Neuropathy occurred in $8(16 \%)$ controls, being just transient in 2 cases and remaining as a permanent complication in others.

Type and number of the analysed complications were similar across the two groups; there were no statistically significant differences between them.

\section{Comparison of treatment efficacy}

As part of the efficacy assessment, the recanalisation following thermal ablation was evaluated, as well as recurrence of varicose veins and quantitative VCSS changes after two different treatments.

Subsequent ultrasound scans showed recanalisation in $5(9.6 \%)$ subjects from the SVS group. The preserved GSV stump reopened proximally to the femoral vein in 3 cases. In each case recanalisation involved a 4-5 cm long segment and was due to the collateral vein insertion at this site. Two patients experienced recanalisation at the mid-femur. In 1 case it involved a 15-cm-long GSV segment, which resulted in recurrent varicose veins in the knee area. In another case, recanalisation involved a $3-4 \mathrm{~cm}$ long segment and was due to the collateral vein insertion at this site. All reported cases of vein reopening were observed during the follow-up evaluation at 6 months. However, the recanalised segments have not extended in these individuals over the 3-year follow-up.

Varicose vein recurrence was observed in 6 (11.5\%) subjects in the SVS group. Three cases of recurrence were due to insufficiency of the anterior accessory great saphenous vein (AAGSV), including 1 case with concomitant GSV segmental recanalisation (a female patient with a 15-cm-long GSV segment reopening) in the distal portion of the femur. Two patients experienced recurrence due to SSV insufficiency, and it involved the posterior portion of the crus. In 1 case the observed recurrence in the knee region was related to femoral perforator vein insufficiency.

In the control group, recurrence was also observed in $6(12 \%)$ patients. Two cases of recurrence due to insufficiency of the anterior accessory great saphenous vein (AAGSV) were noted, although the vessel had been ligated during crossectomy. A single case of recurrence due to insufficiency of the posterior thigh circumflex vein (PTCV) was observed. Two patients experienced recurrence due to SSV insufficiency. In 1 case the observed recurrence was related to femoral perforator vein insufficiency. 
Table V. Mean VCSS score at baseline and after SVS or conventional surgery

\begin{tabular}{|lcccccc|}
\hline Attribute & \multicolumn{3}{c}{ SVS group } & \multicolumn{2}{c|}{ Control group } \\
\cline { 2 - 7 } & At baseline & $\begin{array}{c}\text { After } \\
\text { treatment }\end{array}$ & $\begin{array}{c}\text { Statistical } \\
\text { significance }(p)\end{array}$ & At baseline & $\begin{array}{c}\text { After } \\
\text { treatment }\end{array}$ & $\begin{array}{c}\text { Statistical } \\
\text { significance }(p)\end{array}$ \\
\hline Pain & 1.55 & 0.096 & $<0.001$ & 1.72 & 0.12 & $<0.001$ \\
\hline $\begin{array}{l}\text { Varicose veins } \\
(>4 \text { mm diameter) }\end{array}$ & 2 & 0.13 & $<0.001$ & 2 & 0.12 & $<0.001$ \\
\hline Venous oedema & 1.48 & 0.28 & $<0.001$ & 1.64 & 0.34 & $<0.001$ \\
\hline Skin pigmentation & 0.5 & 0.51 & $>0.05$ & 0.66 & 0.7 & $>0.05$ \\
\hline Inflammation & 0.5 & 0.038 & $<0.01$ & 0.5 & 0.18 & $<0.05$ \\
\hline Induration & 0.51 & 0.15 & $<0.05$ & 0.66 & 0.16 & $<0.01$ \\
\hline No. of active ulcers & 0.13 & 0 & $>0.05$ & 0.16 & 0 & $>0.05$ \\
\hline Active ulcer duration & 0.17 & 0 & $>0.05$ & 0.24 & 0 & $>0.05$ \\
\hline Active ulcer diameter [cm] & 0.13 & 0 & $>0.05$ & 0.18 & 0 & $>0.05$ \\
\hline Compression therapy & 0.25 & 0.55 & $>0.05$ & 0.52 & 0.58 & $>0.05$ \\
\hline Mean score & 7.25 & 1.78 & $<0.05$ & 8.28 & 2.2 & $<0.05$ \\
\hline
\end{tabular}

Table $V$ shows the changes in the VCSS score before and after treatment in both groups.

The VCSS-based clinical improvement assessment showed a similar postoperative score decrease in both groups. Both procedures are effective in resolving pain, oedema, inflammatory infiltration and induration. Both eliminate varicose veins as well. The mean VCSS reduction was also similar in SVS and control groups. The efficacy of both methods is therefore equivalent.

\section{Discussion}

Superficial venous reflux is one of the causes of chronic venous incompetence [13]. Hence, stripping the incompetent veins prevents ulceration in patients with varicose veins. In patients with already present ulcers, such intervention improves healing and prevents ulcer recurrence [14]. Classic surgery, however, requires hospitalisation, conduction or general anaesthesia and job absence. It is also an invasive technique.

Endovenous techniques emerged and gradually started receiving more attention over 10 years ago. It is currently known that intravenous thermal laser or radiofrequency ablation effectively resolves reflux in superficial veins, achieving the same effect as after conventional surgery. The rate of effective obliteration ranges from $87 \%$ to $100 \%$ [15-19]. Complete obliteration as a result of steam vein sclerosis was achieved in $90.4 \%$ of our patients. The results are fully comparable to the already published data and include the 3-year follow-up period. The efficacy of thermal ablation is measured by the recanalisation rate of the treated vein. However, comparing vein reopening is quite a big classification challenge, as this may involve different venous segments. According to Merchant, the phenomenon may be addressed using the following categories: complete closure, reopening involving a segment $\leq 5 \mathrm{~cm}$ and recanalisation involving a segment $>5 \mathrm{~cm}$ [20]. The obliteration rate in the SVS group referred to in our material is based on this classification, including patients with no recanalisation. However, the so-called short-segment recanalisation $(\leq 5 \mathrm{~cm})$ is typically associated with the collateral veins inserting into the active vein segment. We do not know how the phenomenon is going to evolve in a long-term follow-up and whether it may lead to varicose vein recurrence. In our 3-year follow-up, the length of the reopened segment has not changed; the patients have not experienced recurrence; and the ultrasound scans have not confirmed venous reflux in the reopened segments. Hence, clinical success was actually achieved in those patients in whom the obliteration was preserved or the reopened segment length did not exceed $5 \mathrm{~cm}$. Varicose vein recurrence is typically observed in most cases of long-segment reca- 
nalisation, i.e. where the active blood flow within a $5 \mathrm{~cm}$ or longer segment of the obliterated vessel was confirmed with clinically significant venous reflux. This reopening pattern and varicose vein recurrence was observed in $1(1.9 \%)$ patient who had undergone steam vein sclerosis. Therefore clinically significant recanalisation occurred only in 1 patient out of the 52-subject group. It shows high SVS efficacy in incompetent vein obliteration, which reaches even $98.1 \%$ ! It is difficult to compare our findings with the observations made by other investigators, as there are only a few reports on steam vein sclerosis. The method has been used in few European centres, and long-term data have not been published yet. Van den Bos et al. published a paper reporting treatment outcomes in 20 patients. Thirteen of 20 treated veins were still obliterated at 6 months, whereas 7 others showed slight signs of recanalisation [21]. In our material, we achieved complete vein closure in the first 20 patients; during the 3-year follow-up, long-segment recanalisation occurred in $1.9 \%$ and short-segment recanalisation in $7.7 \%$ of them [22] The newest paper by Milleret et al. reports the vein reopening rate of $3.9 \%$ at 6 months [23]. Undoubtedly, this phenomenon requires further research. However, even now SVS can be said to offer good outcomes in terms of successful vein obliteration.

Although most authors refer to recanalisation rate as the main efficacy indicator, it is the recurrence of varicose veins which ultimately determines whether thermal ablation was successful. There are many underlying causes of varicose vein recurrence, the most common being the wrong choice of surgical strategy, surgeon's technical error, neovascularisation or disease progression [24]. Whilst we can affect the first two factors, the others remain beyond human control. The varicose vein recurrence rates in our study were $11.5 \%$ and $12 \%$ for the SVS and control group, respectively. The difference is not significant and the causes of the recurrence are the same in both groups, namely incompetent vessel remainders and vascular disease progression.

A huge advantage of thermal ablation of the venous trunk (including SVS) is avoiding an incision within the inguinal or popliteal area and the absence of vein separation from its tributaries at the saphenofemoral or saphenopopliteal junction. Neovascularisation is a well-established cause of varicose vein recurrence $[24,25]$. That is why reoperation is more challenging and is associated with an increased risk of lymphatic or infectious complications. Neovascularisation following thermal venous obliteration has not been reported yet, and its risk is very low indeed $[26,27]$. When performed accurately, thermal ablation takes place inside the blood vessel and, as a result, the inflammatory response should be relatively low. The preserved GSV stump is typically joined to the superficial epigastric vein, which enables undisturbed blood drainage from the lower abdomen.

Paraesthesias and sensory loss occur relatively often after classic surgery and are associated with vein stripping from the medial malleolus. It is difficult to avoid this complication, so if avoided it is usually a random occurrence. Saphenous nerve damage occurs in $23 \%$ to $40 \%$ of patients undergoing total saphenectomy and $7-19 \%$ of patients undergoing subtotal saphenectomy (above the knee). Limited stripping promotes saphenous nerve recovery and reduces its permanent damage [28]. Saphenous neuropathy in our study sample was equally frequent in the SVS and the control group. It should be noted that we did not observe saphenous nerve damage in patients in whom stripping or SVS had been performed at the $1 / 3$ of the crus or higher.

Skin pigmentation after varicose vein surgery is the most unwanted complication in young female patients. It can develop after any type of surgery, being the most common after sclerotherapy (10-30\%), due to the thrombotic inflammation of sclerosed vein segments [29]. In patients after classic surgery, it is usually caused by a haematoma, forming and resolving at the site of the stripped vein. Thermal vein obliteration, typically considered to produce better aesthetic outcomes, also carries this risk. That is why the user manuals of these surgical devices include a warning note of potential skin pigmentation, thus protecting themselves from potential claims for damages. Skin pigmentation after thermal vein ablation is usually due to phlebitis involving the GSV or SSV. Permanent, persistent pigmentation in our group affected $7.6 \%$ of SVS subjects and $4 \%$ of controls treated with stripping and ligation. The pigmentation manifested in most patients as linear brunescent streaks involving the distal third of the thigh and the upper third of the lower leg medially. It was accompanied by intense intravascular blood coagulation. The involved vein was very shallow in these individuals, and they were informed in advance that such a complication was likely to occur. It should be noted that the diameter of the ablated veins was 
quite large - over 9-10 $\mathrm{mm}$ - in all discussed cases. The available published reports virtually neglect the issue of skin pigmentation. There are only a few that mention the complication, and its incidence is far below $10 \%[15,30]$.

\section{Conclusions}

The detailed efficacy and safety analysis of thermal obliteration (steam vein sclerosis - SVS) shows that it is a safe and a simple method, offering efficacy similar to that of conventional surgery. The recurrence rate, complication rate and the quantitative VCSS score reduction of both methods are similar. Therefore, SVS can be recommended as an effective varicose vein treatment.

\section{Conflict of interest}

The authors declare no conflict of interest.

\section{References}

1. Winterborn RJ, Corbett CR. Treatment of varicose veins: the present and the future - a questionnaire survey. Ann R Coll Surg Engl 2008; 90: 561-4.

2. Perrin M, Guidicelli H, Rastel D. Surgical techniques used for the treatment of varicose veins: survey of practice in France. J Mal Vasc 2003; 28: 277-86

3. Perkins JM. Standard varicose vein surgery. Phlebology 2009; 24: 34-41.

4. Wood JJ, Chant H, Laugharne M, et al. A prospective study of cutaneous nerve injury following long saphenous vein surgery. Eur J Vasc Endovasc Surg 2005; 30: 654-8.

5. Miller GV, Lewis WG, Sainsbury JR, et al. Morbidity of varicose vein surgery: auditing the benefit of changing clinical practice. Ann R Coll Surg Engl 1996; 78: 345-9.

6. Critchley G, Handa A, Maw A, et al. Complications of varicose vein surgery. Ann R Coll Surg Engl 1997; 79: 105-10.

7. Wright AP, Berridge DC, Scott DJ. Return to work following varicose vein surgery: influence of type of operation, employment and social status. Eur J Vasc Endovasc Surg 2006; 31: 553-7.

8. Fischer R, Linde N, Duff C, et al. Late recurrent saphenofemoral junction reflux after ligation and stripping of the greater saphenous vein. J Vasc Surg 2001; 34: 236-40.

9. Negus D. Recurrent varicose veins: a national problem. $\mathrm{Br}$ J Surg 1993; 80: 823-4.

10. Politowski M, Szpak E, Marszałek Z. Treatment of varicose veins of the lower extremities with the aid of electrocoagulation. Pol Przegl Chir 1964; 36: 7-14.

11. Milleret R. Innovations in the treatment of saphenous trunks. In: Innovative treatment of venous disorders. Wittens C (ed.). Edizioni Minerva Medica, Turin 2009; 159-70.

12. Thomis S, Verbrugghe P, Milleret R, et al. Steam ablation versus radiofrequency and laser ablation: an in vivo histological comparative trial. Eur J Vasc Endovasc Surg 2013; 46: 378-82.
13. Labropoulos N, Leon M, Nicolaides AN, et al. Superficial venous insufficiency: correlation of anatomic extent of reflux with clinical symptoms and signs. J Vasc Surg 1994; 20: 953-8.

14. Howard DP, Howard A, Kothari A, et al. The role of superficial venous surgery in the management of venous ulcers: a systematic review. Eur J Vasc Endovasc Surg 2008; 36: 458-65.

15. Proebstle TM, Vago B, Alm J, et al. Treatment of the incompetent great saphenous vein by endovenous radiofrequency powered segmental thermal ablation: first clinical experience. J Vasc Surg 2008; 47: 151-6.

16. Ogawa T, Hoshino S, Midorikawa $\mathrm{H}$, et al. Clinical results of radiofrequency endovenous obliteration for varicose veins. Surg Today 2005; 35: 47-51.

17. Almeida JI, Raines JK. Radiofrequency ablation and laser ablation in the treatment of varicose veins. Ann Vasc Surg 2006; 20: 547-52.

18. Gibson KD, Ferris BL, Polissar N, et al. Endovenous laser treatment of the small [corrected] saphenous vein: efficacy and complications. J Vasc Surg 2007; 45: 795-801.

19. Desmyttère J, Grard C, Wassmer B, et al. Endovenous 980-nm laser treatment of saphenous veins in a series of 500 patients. J Vasc Surg 2007; 46: 1242-7.

20. Merchant RF, DePalma RG, Kabnick LS. Endovascular obliteration of saphenous reflux: a multicenter study. J Vasc Surg 2002; 35: 1190-6.

21. van den Bos RR, Milleret R, Neumann M, et al. Proof-of-principle study of steam ablation as novel thermal therapy for saphenous varicose veins. I Vasc Surg 2011; 53: 181-6.

22. Mlosek RK, Wozniak W, Gruszecki L, et al. The use of a novel method of endovenous steam ablation in treatment of great saphenous vein insufficiency: own experiences. Phlebology 2014; 29: 58-65.

23. Milleret R, Huot L, Nicolini P, et al. Great saphenous vein ablation with steam injection: results of a multicentre study. Eur J Vasc Endovasc Surg 2013; 45: 391-6.

24. Kostas T, Ioannou CV, Touloupakis E, et al. Recurrent varicose veins after surgery: a new appraisal of a common and complex problem in vascular surgery. Eur I Vasc Endovasc Surg 2004; 27: $275-82$.

25. Heim D, Negri M, Schlegel U, et al. Resecting the great saphenous stump with endothelial inversion decreases neither neovascularization nor thigh varicosity recurrence. J Vasc Surg 2008; 47: 1028-32.

26. Theivacumar NS, Dellagrammaticas D, Beale RJ, et al. Fate and clinical significance of saphenofemoral junction tributaries following endovenous laser ablation of great saphenous vein. $\mathrm{Br}$ J Surg 2007; 94: 722-5.

27. Kianifard B, Holdstock JM, Whiteley MS. Radiofrequency ablation (VNUS closure) does not cause neo-vascularisation at the groin at one year: results of a case controlled study. Surgeon 2006; 4: 71-4.

28. Holme JB, Skajaa K, Holme K. Incidence of lesions of the saphenous nerve after partial or complete stripping of the long saphenous vein. Acta Chir Scand 1990; 156: 145-8.

29. Goldman MP, Sadick NS, Weiss RA. Cutaneous necrosis, telangiectatic matting, and hyperpigmentation following sclero- 
therapy. Etiology, prevention and treatment. Dermatol Surg 1995; 21: 19-29.

30. Ferreira A, Ramos J, Cerqueira A, et al. Radiofrequency-powered segmental thermal ablation in chronic venous disorders: a single center experience. Rev Port Cir Cardiotorac Vasc 2011; 18: 123-7.

Received: 2.11.2014, accepted: 3.12.2014. 